\title{
Ultrasonographic evaluation of antenatal umbilical cord coiling index (aUCI) in second trimester of gestation and pregnancy outcome
}

\author{
Richa Arora*, Manjit K. Mohi, Manpreet Kaur, Gurdip Kaur, Satinder P. Kaur
}

Department of Obstetrics and Gynecology, Government Medical College, Patiala, Punjab, India

Received: 01 September 2018

Accepted: 28 September 2018

\author{
*Correspondence: \\ Dr. Richa Arora, \\ E-mail: richngold@yahoo.com
}

Copyright: () the author(s), publisher and licensee Medip Academy. This is an open-access article distributed under the terms of the Creative Commons Attribution Non-Commercial License, which permits unrestricted non-commercial use, distribution, and reproduction in any medium, provided the original work is properly cited.

\begin{abstract}
Background: To evaluate the role of antenatal umbilical cord coiling index (aUCI) obtained during routine second trimester ultrasound as a predictor of perinatal outcome.

Methods: Fetal ultrasound of 100 pregnant women was done between 18-24 weeks of gestation. Antenatal UCI was calculated as a reciprocal value of the distance between a pair of coils. Patients were followed up till delivery for perinatal outcome. UCI was correlated with: (1) gestational age (2) mode of delivery, (3) presence of meconiumstained amniotic fluid, (4) APGAR scores and (5) birth weight.

Results: aUCI was categorized as hypocoiled, normocoiled or hypercoiled. Hypocoiled cord was associated with LBW (1\%), preterm delivery (1\%) while hypercoiled cord was associated with LBW (4\%). No statistical difference was found for birth weight, gestational age, APGAR scores and MSAF between the groups with normal and abnormal aUCI.

Conclusions: In present study, no association was found between abnormal aUCI with higher prevalence of interventional delivery, presence of MSAF, preterm and LBW. Therefore, more specific parameters need to be developed as promising prognostic marker for predicting adverse perinatal outcome and further studies are needed to test this hypothesis.
\end{abstract}

Keywords: Antenatal umbilical cord coiling index, aUCI, Midtrimester, Pregnancy outcome, ultrasonography

\section{INTRODUCTION}

The umbilical cord is a tubular structure which connects the fetus to the maternal placenta. It acts a transport pathway for the blood from the mother to the fetus and vice versa. Umbilical cord develops from the amnion between 4 th to 8 th week and by the end of 5 th week, blood flow is established. ${ }^{1}$ It is composed of two umbilical arteries, one umbilical vein and allantois, which lie embedded in Wharton's jelly and covered with a single layer of amnion. The length of the umbilical cord ranges from $30 \mathrm{~cm}$ to $100 \mathrm{~cm}$, with an average of 50 $60 \mathrm{~cm} .^{2,3}$ Cord with length less than $30 \mathrm{~cm}$ is considered short and is seen in approximately $6 \%$ of cases. ${ }^{4}$ Short cord may be seen in cases of premature placental separation and delayed descent of the fetus during labor. ${ }^{5}$ Also, short cords have been found to be associated with fetal growth restriction, increased incidence of congenital anomalies, intrapartum fetal distress and demise. ${ }^{3}$ Long cords are frequently associated with increased maternal age, maternal systemic disease, fetal anomalies, vertex presentation, male factors and increased birth weight. ${ }^{6}$ The diameter of umbilical cord increase from $3.19 \pm 0.40$ $\mathrm{mm}$ at 10 weeks gestation to a maximum of $16.72 \pm 2.57$ $\mathrm{mm}$ at 33-35 weeks, which again decreases by term due to reduction in water content of Wharton's jelly. ${ }^{2}$

Among its structural uniqueness, the most intriguing character is the umbilical cord coiling, where the contents of umbilical cord course in a coiled fashion. Various 
theories have been put forward to explain umbilical cord coiling, a few of which include twisting as inherent property of the cord itself or twisting due to fetal movements. ${ }^{7}$ Coiling protects the cord by preventing compression of its vessels. ${ }^{8}$ The average number of coils seen in a cord is around $40 .{ }^{9}$ It is believed that "the cord does not grow in length by any increase in the number of twists but by a progressive increase in the length of the pitch of the primary helix". ${ }^{10}$ Coiling develops as early as 4 weeks after conception and can be seen by ultrasonography in first trimester of pregnancy. ${ }^{11}$

The helical structure of umbilical cord is a matter of discussion. There have been various studies to understand the origin and significance of this helical pattern. Presently, umbilical cord helices are measured in terms of umbilical cord coiling index, as proposed by Strong et al. " $\mathrm{NCI}$ is obtained by dividing the total number of complete vascular coils by the umbilical cord length after the delivery of placenta." Normal UCI has been reported to be approximately 1 coil $/ 5 \mathrm{~cm}$ of umbilical cord length or $0.20 / \mathrm{cm}^{13}$ Degani et al have described a technique for estimating antenatal coiling index during ultrasound examination. ${ }^{14}$

The present study is being conducted to evaluate the role of umbilical cord coiling index in the second trimester of gestation and pregnancy outcome in the form of gestational age, APGAR score, meconium stained liquor and birth weight.

\section{METHODS}

This prospective cross-sectional study was performed at Department of Obstetrics and Gynaecology, Government Medical College and Rajindra Hospital, Patiala to evaluate the role of antenatal umbilical cord coiling index (aUCI) at 18 to 24 weeks of gestation and pregnancy outcome.

\section{Inclusion criteria}

- A total of hundred pregnant women with normal singleton pregnancy, absence of gross congenital fetal malformations, and planned delivery at the institution.

\section{Exclusion criteria}

- Multifetal pregnancy and any fetal malformation.

Ultrasonography was done between 18 to 24 weeks. Antenatal UCI was measured in a free-floating loop of cord as "a reciprocal value of the distance between the inner edge of one artery to the outer edge of the same artery at the adjacent umbilical twist along the ipsilateral cord side. (antenatal UCI=1/distance in centimeters)." as described by Degani. ${ }^{14}$ Values of UCI were arranged in ascending order and $10^{\text {th }}, 50^{\text {th }}$ and $90^{\text {th }}$ percentile calculated. Hypo-coiled cord were defined as those with
aUCI lower than the 10th percentile, normocoiled cordbetween $10^{\text {th }}$ percentile and $90^{\text {th }}$ percentile, and hypercoiled cord -higher than the $90^{\text {th }}$ percentile.

The labor and delivery data was collected- mode of delivery (vaginal vs cesarean), gestational age at delivery (preterm <37wks, term-37-42 weeks, post term >42wks), meconium staining of amniotic fluid, birth weight (LBW<2500gm, VLBW <1500gm, extreme LBW $<1000 \mathrm{gm}$ ) and APGAR score at 1 (abnormal<4) and 5 minutes (abnormal $<7$ ).

\section{Statistical analysis}

Results were calculated as mean \pm SD and percentiles. Statistical analysis was performed using SPSS version 17.0 and one-way ANOVA, student t-test and chi square test. Pearson's correlation analysis was used to establish the degree of relationship. $\mathrm{p}$ value of less than 0.05 was considered statistically significant.

\section{RESULTS}

100 patients irrespective of their previous obstetrics history were included in the study. Mean gestation at ultrasonography was 20.97 weeks. Maximum distance between two loops of coils was found to be $6 \mathrm{~cm}$ and minimum distance was $0.60 \mathrm{~cm}$ with the mean inter-coil distance of $1.94 \pm 0.06 / \mathrm{cm}$. Mean UCI of 100 women was $0.56 \pm 0.01 / \mathrm{cm}$. Minimum UCI was $0.17 / \mathrm{cm}$ and the maximum UCI was $1.67 / \mathrm{cm}$ (Figure-1).

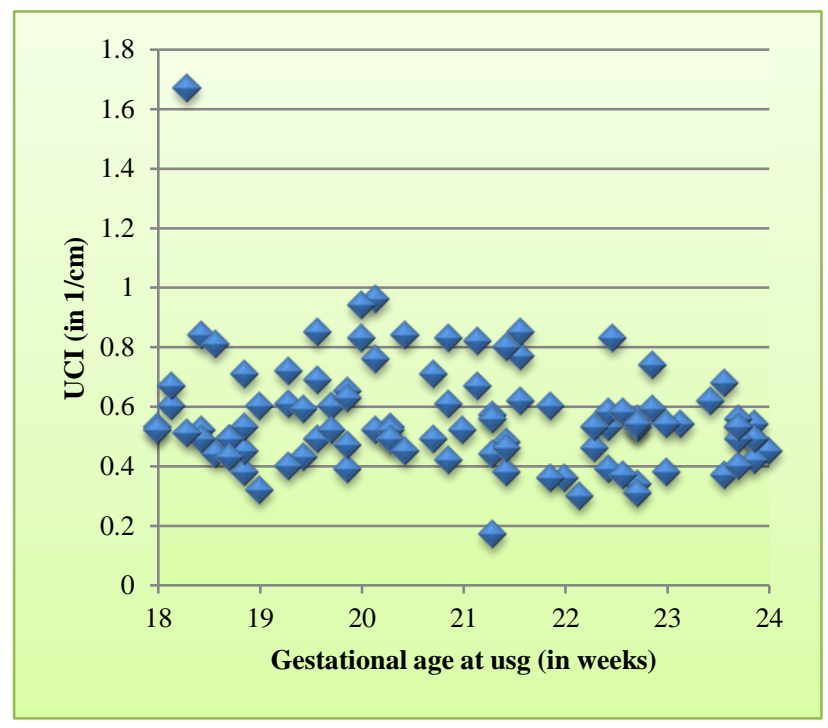

Figure 1: Distribution of umbilical cord coiling index at 18-24 weeks of gestation.

$12(12 \%)$ women had hypocoiled cords $(\mathrm{UCI}<0.38 / \mathrm{cm})$, $78(78 \%)$ had normocoiled cords $(\mathrm{UCI}=0.38-0.82 / \mathrm{cm})$ while the rest $10(10 \%)$ had hypercoiled cords (UCI>0.82/cm). 77 (77\%) women had term deliveries, 19 (19\%) delivered between 32 weeks to 36.6 weeks while 3 (3\%) had very preterm deliveries. 
Only $1(1 \%)$ woman delivered at 42 weeks gestation. Hypocoiled cord was seen in $1 \%$ cases who had preterm delivery while no case with preterm delivery had hypercoiled cord.

Statistically, there was no significant difference for gestational age at delivery between women with normal and abnormal a UCI (Table-1). 60 (60\%) women had vaginal delivery, $37(37 \%)$ underwent LSCS and the remaining $3(3 \%)$ had instrumental delivery with outlet forceps.
5\% cases with hypocoiled umbilical cord had LSCS and $1 \%$ cases had forceps delivery while $4 \%$ cases with hypercoiled umbilical cord had LSCS.

No difference was seen between mode of delivery for normal and abnormal aUCI (Table 2). 67 (67\%) newborns had birth weight between $2.5 \mathrm{~kg}$ to $3.5 \mathrm{~kg} .27$ (27\%) newborns were LBW, $3(3 \%)$ newborns were very LBW and $2(2 \%)$ newborns were extremely LBW. Only 1 (1\%) newborn had birth weight of $>3.5 \mathrm{~kg}$.

Table 1: Mean and distribution of UCI at different gestations of birth.

\begin{tabular}{|c|c|c|c|c|c|c|c|}
\hline \multirow[b]{2}{*}{ Gestational age (in weeks) } & \multicolumn{7}{|c|}{ UCI (in 1/cm) } \\
\hline & Mean \pm SD & $\begin{array}{l}p \\
\text { value }\end{array}$ & $\begin{array}{l}\text { Hypocoiled } \\
<\mathbf{0 . 3 8 0}\end{array}$ & $\begin{array}{l}\text { Normocoiled } \\
0.381-0.829\end{array}$ & $\begin{array}{l}\text { Hypercoiled } \\
>0.829\end{array}$ & $p$ value & Total \\
\hline$\leq 31.6$ & $0.64 \pm 0.16$ & \multirow{5}{*}{$\begin{array}{l}0.389 \\
\text { NS }\end{array}$} & 0 & 3 & 0 & \multirow{5}{*}{$\begin{array}{l}0.054 \\
\text { NS }\end{array}$} & 3 \\
\hline$>31.6-36.6$ & $0.52 \pm 0.13$ & & 1 & 18 & 0 & & 19 \\
\hline$>36.6-41.6$ & $0.58 \pm 0.20$ & & 10 & 57 & 10 & & 77 \\
\hline$>41.6$ & 0.38 & & 1 & 0 & 0 & & 1 \\
\hline Total & & & 12 & 78 & 10 & & 100 \\
\hline
\end{tabular}

Table 2: Mean and distribution of UCI for different mode of delivery.

\begin{tabular}{|c|c|c|c|c|c|c|c|}
\hline \multirow[b]{2}{*}{ Mode of delivery } & \multicolumn{7}{|c|}{ UCI (in 1/cm) } \\
\hline & Mean \pm SD & $p$ value & $\begin{array}{l}\text { Hypocoiled } \\
\leq \mathbf{0 . 3 8 0}\end{array}$ & $\begin{array}{l}\text { Normocoiled } \\
\mathbf{0 . 3 8 1 - 0 . 8 2 9}\end{array}$ & $\begin{array}{l}\text { Hypercoiled } \\
>0.829\end{array}$ & $p$ value & Total \\
\hline Vaginal & $0.57 \pm 0.15$ & \multirow{4}{*}{$0.468 \mathrm{NS}$} & 6 & 48 & 6 & \multirow{4}{*}{$0.765 \mathrm{NS}$} & 60 \\
\hline Outlet forceps & $0.43 \pm 0.23$ & & 1 & 2 & 0 & & 3 \\
\hline LSCS & $0.57 \pm 0.23$ & & 5 & 28 & 4 & & 37 \\
\hline Total & & & 12 & 78 & 10 & & 100 \\
\hline
\end{tabular}

Table 3: Mean and distribution of UCI for different birth weights.

\begin{tabular}{|c|c|c|c|c|c|c|c|}
\hline \multirow[b]{2}{*}{ Birth weight (in kg) } & \multicolumn{7}{|c|}{ UCI (in 1/cm) } \\
\hline & Mean \pm SD & $p$ value & $\begin{array}{l}\text { Hypocoiled } \\
\leq \mathbf{0 . 3 8 0}\end{array}$ & $\begin{array}{l}\text { Normocoiled } \\
0.381-0.829\end{array}$ & $\begin{array}{l}\text { Hypercoiled } \\
>0.829\end{array}$ & $p$ value & Total \\
\hline$\leq 1.0$ & $0.65 \pm 0.17$ & \multirow{6}{*}{$0.523 \mathrm{NS}$} & 0 & 2 & 0 & \multirow{6}{*}{$0.739 \mathrm{NS}$} & 2 \\
\hline $1.0-1.5$ & $0.66 \pm 0.17$ & & 0 & 3 & 0 & & 3 \\
\hline $1.5-2.5$ & $0.60 \pm 0.25$ & & 1 & 22 & 4 & & 27 \\
\hline $2.5-3.5$ & $0.54 \pm 0.18$ & & 11 & 50 & 6 & & 67 \\
\hline$>3.5$ & 0.6 & & 0 & 1 & 0 & & 1 \\
\hline Total & & & 12 & 78 & 10 & & 100 \\
\hline
\end{tabular}

$1 \%$ cases with hypocoiled umbilical cord had LBW while $4 \%$ cases with hypercoiled umbilical cord had LBW. No statistical difference of birth weight was seen between normal and abnormal groups of aUCI (Table-3).

Of the 100 women, $23(23 \%)$ had meconium staining of the liquor. Among these, $16(70 \%)$ had evidence of fetal distress by CTG or by intermittent auscultation. 13
(56.5\%) had LSCS due to fetal distress and $3(13 \%)$ had instrumental delivery by outlet forceps to cut short the second stage of labour. No difference for aUCI was seen in cases with MSAF and clear liquor irrespective of gestation age or birth weight (hypocoiled cord-3\%, hypercoiled- 2\%) (Table-4). Similarly, no difference was seen in cases with fetal distress for normal and abnormal aUCI (hypocoiled cord-3\%, hypercoiled cord- 1\%). 
Table 4: mean and distribution of UCI and color of liquor.

\begin{tabular}{|c|c|c|c|c|c|c|c|c|}
\hline \multirow[b]{2}{*}{$\begin{array}{l}\text { Color of } \\
\text { liquor }\end{array}$} & \multirow[b]{2}{*}{$\begin{array}{l}\text { Gestation } \\
\text { (in weeks) }\end{array}$} & \multicolumn{7}{|c|}{ UCI (in 1/cm) } \\
\hline & & Mean UCI & $p$ value & $\begin{array}{l}\text { Hypocoiled } \\
\leq \mathbf{0 . 3 8 0}\end{array}$ & $\begin{array}{l}\text { Normocoiled } \\
0.381-0.829\end{array}$ & $\begin{array}{l}\text { Hypercoiled } \\
>0.829\end{array}$ & $p$ value & Total \\
\hline \multirow{2}{*}{ MSAF } & $<37$ & 0.48 & \multirow{2}{*}{$0.191 \mathrm{NS}$} & 1 & 4 & 0 & \multirow{2}{*}{$\begin{array}{l}0.672 \\
\text { NS }\end{array}$} & 5 \\
\hline & $>37$ & 0.59 & & 2 & 14 & 2 & & 18 \\
\hline \multirow{2}{*}{ Clear } & $<37$ & 0.55 & \multirow{3}{*}{$\begin{array}{l}0.711 \\
\text { NS }\end{array}$} & 0 & 17 & 0 & \multirow{3}{*}{$\begin{array}{l}0.045 \\
\text { NS }\end{array}$} & 17 \\
\hline & $>37$ & 0.57 & & 9 & 43 & 8 & & 60 \\
\hline Total & & & & 12 & 78 & 10 & & 100 \\
\hline
\end{tabular}

\section{DISCUSSION}

The spiral course of the umbilical vessels was first recorded by Berengarius in 1521. It was then confirmed by Columbus in 1559 and by Arantius in 1564 . Umbilical cord coiling may be seen as early as 4 weeks post fertilization, however, mechanism by which coiling occurs, is still a matter of research. Various hypothesis state that coiling may be the result of early fetal activity, hemodynamic factors or anatomical factors like presence of Roach muscle. Coiling is thought to play an important role in protecting the umbilical cord from external pressure, tension, stretching or entanglement. There are multiple studies which have established the association between antenatal and postnatal UCI, which is not surprising as both are a measure of the same phenomeneon. ${ }^{15}$ However, only a few studies have been conducted till date to study correlation of aUCI with perinatal outcome. Also, there is a limited data to suggest optimal time to measure UCI. During first trimester, it is difficult to examine the cord ultrasonographically, while in third trimester, it might be difficult to find a free loop of cord because of reduced volume of amniotic fluid. During the second trimester the amount of amniotic fluid relative to fetal size is usually greater than at term, allowing visualization of a larger part of the cord. Furthermore, it is generally believed that umbilical coiling is fully developed by the end of the first trimester and does not change after this, the cord growing continually by lengthening between coils rather than by generation of new coils. Therefore, second trimester of gestation appears to be suitable time, though more studies are required to confirm these findings.

In a study conducted between 14-16 weeks of gestation, they found hypocoiled cords to be associated with intrauterine growth restriction, however, no relation was seen with preterm birth, MSAF or fetal distress. ${ }^{16}$ In studies that were conducted in third trimester, both hypocoiled and hypercoiled cord were found to be associated with FGR and increased incidence of interventional delivery. ${ }^{17}$ Among different studies conducted during the second trimester of gestation, Jo et al reported high incidence of preterm birth and LBW in hypocoiled group but did not find any significant correlation. ${ }^{18}$ Sharma et al found significant association between abnormal coiling and increased incidence of preterm birth, LBW and low APGAR scores at 5 minutes. ${ }^{19}$ Predanic et al reported significant association of abnormal coiling with SGA and non-reassuring fetal status in labor but no statistical difference was seen for APGAR score, MSAF or increased incidence of interventional deliveries. ${ }^{21}$

Morteza Tahmasebi et al conducted a study in 255 women after 20 weeks of gestation but found no statistically significant correlation between aUCI and LBW, 5- min APGAR score and MSAF. ${ }^{21}$ Siddiqui et al found increased incidence of interventional delivery with hypercoiling which was statistically significant, but no statistical significance of SGA, MSAF or low APGAR scores with hypocoiling though their prevalence was higher in hypocoiling group. ${ }^{22}$ The present study did not find any association between abnormal coiling and adverse perinatal outcome. Therefore, the results of already reported studies, including the present study, are significantly different. Also, there is a limited data to suggest optimal time to measure UCI. It may be because UCI changes continuously in utero. It has been seen that the antenatal UCI follows approximately normal distribution. The UCI is significantly higher near the fetal insertion than in the middle of the umbilical cord, which in turn is higher in the segment near to the placental insertion.

\section{CONCLUSION}

Pregnancies with abnormal umbilical cord coiling index may have normal outcome, however, further studies are necessary to establish these findings. Hence, we recommend evaluation of this parameter with large groups to find definite association which might serve as a predictive marker for fetal health in the near future.

\section{ACKNOWLEDGMENTS}

Authors would like to thank colleagues who provided their expertise which greatly assisted the research work. Authors would also like to thank patients who consented to be a part of this study with full faith.

Funding: No funding sources

Conflict of interest: None declared 
Ethical approval: The study was approved by the Institutional Ethics Committee

\section{REFERENCES}

1. Schöni-Affolter F, Dubuis-Grieder C, Strauch E. The umbilical cord. 2007; Available at: http://www.embryology.ch/anglais/fplacenta/ cordon01.html.

2. Di Naro E, Ghezzi F, Raio L, Franchi M, D’Addario V. Umbilical cord morphology and pregnancy outcome. Eur J Obstet Gynecol Reprod Biol. 2001;96(2):150-7.

3. Cunningham FG, Leveno KJ, Bloom SL, Hauth JC, Rouse DJ, Spong CY. Williams Obstetrics. $\left(23^{\text {rd }}\right.$ ed $)$ New York: McGraw Hill Medical; 2010.

4. Van den Broek N, Ntonya C, Kayira E, White S. Neilson JP. Preterm birth in rural Malawi: high incidence in ultrasound-dated population. Human Reproduct, 2005;20(11):3235-7.

5. Hanretty K. Obstetrics Illustrated. Edinburgh: $7^{\text {th }}$ Ed. Churchill Livingstone Elsevier; 2010.

6. Muppala H, Bedoya-Ronga A, Martindale E. Abnormally long umbilical cord with marked spiraling and true knots: a case report. Int J Gynecol Obstet. 2007;7(1):7.

7. ShaluGupta M, Krishnan J. Umbilical coiling index. J Obstet Gynecol India. 2006;56(4):315-9.

8. Strong TH Jr, Elliott JP, Radin TG. Non-coiled umbilical blood vessels: a new marker for the foetus at risk. Obstet Gynecol. 1993;81(3):409-11.

9. Ross JA, Jurkovic D, Zosmer N, Jauniaux E, Hacket E, Nicolaides KH. Umbilical cord cysts in early pregnancy. Obstet Gynecol. 1997;89(3):442-5.

10. Malpas P and Symonds EM. Observations on the structure of the human umbilical cord. Surg Gynecol Obstet 1966;123(4):746-50.

11. Lacro RV, Jones KL, Benirschke K. The umbilical cord twist: origin, direction, and relevance. American J Obstet Gynecol. 1987;157(4):833-8.

12. Strong TH Jr, Jarles DL, Vega JS, Feldman DB. The umbilical coiling index. Am J Obstet Gynecol 1994;170(1):29-32

13. Machin GA, Ackerman J, Gilbert-Barness E. Abnormal umbilical cord coiling is associated with adverse perinatal outcomes. Pediatr Dev Pathol 2000;3(5):462-71.
14. Degani S, Lewinsky RM, Berger H, Spiegel D. Sonographic estimation of umbilical coiling index and correlation with Doppler flow characteristics. Obstet Gynecol 1995;86(6):990-3.

15. Predanic M, Perni SC, Chasen ST, Baergen RN, Chervenak FA. Assessment of umbilical cord coiling during the routine fetal sonographic anatomic survey in the second trimester. J Ultrasound Med. 2005;24(2):185-91.

16. Degani S, Leibovich Z, Shapiro I, Gonen R, Ohel G. Early second-trimester low umbilical coiling index predicts small-for-gestational-age fetuses. J Ultrasound Med. 2001;20:1183-8.

17. De Laat MW, Franx A, Nikkels PG, Visser GH. Prenatal ultrasonographic prediction of the umbilical coiling index at birth and adverse pregnancy outcome. Ultrasound Obstet Gynecol. 2006;28(5):704-9.

18. Qin Y, Lau TK, Rogers MS. Second-trimester ultrasonographic assessment of the umbilical coiling index. Ultrasound Obstet Gynecol. 2002;20(5):45863.

19. Sharma B, Bhardwaj N, Gupta S, Gupta PK, Verma A, Malviya K. Association of Umbilical Coiling Index by Colour Doppler Ultrasonography at 18-22 Weeks of Gestation and Perinatal Outcome. J Obstet Gynaecol India. 2012;62(6):650-4.

20. Degani S, Leibovich Z, Shapiro I, Gonen R, Ohel G. Early second-trimester low umbilical coiling index predicts small-for-gestational-age fetuses. J Ultrasound Med. 2001;20(11):1183-8.

21. Tahmasebi $M$ and Alighanbari R. Evaluation of umbilical cord thickness, cross-sectional area, and coiling index as predictors of pregnancy outcome. Indian J Radiol Imaging. 2011;21(3):195-8.

22. Siddiqui MA, Ahmad I, Ullah E, Khalid M, Ahmad M, Ahmad M. Prediction of adverse perinatal outcome using antenatal umblical cord coiling index. Pediatr Therapeut. 2011;1(2):79.

Cite this article as: Arora R, Mohi MK, Kaur M, Kaur G, Kaur SP. Ultrasonographic evaluation of antenatal umbilical cord coiling index (aUCI) in second trimester of gestation and pregnancy outcome. Int J Reprod Contracept Obstet Gynecol 2018;7:4623-7. 